\title{
Incidence of cancer and exposure to toluene diisocyanate and methylene diphenyldiisocyanate: a cohort based case-referent study in the polyurethane foam manufacturing industry
}

\author{
Lars Hagmar, Ulf Strömberg, Hans Welinder, Zoli Mikoczy
}

\begin{abstract}
Objective-To assess the association between occupational exposure to toluene diisocyanate or methylene diphenyldiisocyanate and risk of cancer.

Design-A cohort based case-referent study. Study base-7023 subjects employed during the period 1958 to 1987 in nine Swedish polyurethane foam manufacturing plants.

Main outcome measures-Odds ratios adjusted with respect to the matching factors (age at risk, calendar year at risk, sex, and plant), calculated from the conditional logistic regression model.

Results-A non-significant association was found between high exposure to isocyanates and prostate cancer (OR $2 \cdot 66,90 \%$ confidence interval $(90 \%$ CI $0 \cdot 39-18 \cdot 1)$, which was not enhanced when an induction latency period of 10 years was applied. An assocation between isocyanate exposure and colon cancer was even weaker. No associations were seen for non-Hodgkin's lymphoma and rectal cancer.

Conclusions-The tentative associations, derived from a previous cohort study, between isocyanate exposure and excess risk for nonHodgkin's lymphoma and rectal cancer were not supported. Instead, non-significant associations with prostate cancer, and possibly colon cancer, were seen.
\end{abstract}

(British fournal of Industrial Medicine 1993;50:1003-1007)

Toluene diisocyanate (TDI), which is used in huge amounts in the polyurethane manufacturing indus-

Department of Occupational and Environmental Medicine, University Hospital, S-221 85 Lund, Sweden.

L Hagmar, U Strömberg, H Welinder, Z Mikoczy try, is an animal carcinogen. ${ }^{12}$ This is probably due to the formation of toluenediamine (TDA) when TDI comes into contact with water in body fluids. 2,4-Toluenediamine (2,4-TDA) is an established animal carcinogen, ${ }^{1}$ and has been detected in urine and plasma from employees in the polyurethane foam manufacturing industry. ${ }^{3}$ Another aromatic isocyanate, methylene diphenyldiisocyanate (MDI), is used as an alternative to TDI in this industry. MDI is mutagenic, ${ }^{4}$ but has not been tested for carcinogenicity. Similarly to TDI, it may be converted to an aromatic amine, methylenedianiline (MDA), in the body. 4,4-Methylenedianiline (4,4-MDA) is an established animal carcinogen. ${ }^{1}$

We have now performed a nested case-referent study of incidence of cancer within a cohort of workers from nine Swedish polyurethane foam manufacturing plants, where TDI and MDI have been handled. A previous cohort study on 4154 workers employed for at least one year in these plants displayed no overall increase in risk of cancer, but non-Hodgkin's lymphomas and rectal cancers showed non-significant excesses. ${ }^{5}$ The risk estimate for these two tumours increased both when applying at least a 10 years induction latency period and when excluding all but apparently exposed subjects from the calculations. The aim of the present study was to assess more thoroughly the association between exposure to TDI or MDI and risk of cancer.

\section{Subjects and methods}

STUDY BASE

The study base comprised the employees from nine Swedish polyurethane foam manufacturing plants, in which TDI and MDI had been used. Altogether 7023 subjects had been employed for at least one day during the period 1958 to 1987 (table 1). A cohort study on mortality and incidence of cancer has previously been performed on 
Table 1 Vital status as of 31 December, 1987 in the study base of 7023 workers employed for at least one day in the polyurethane foam manufacturing industry

\begin{tabular}{|c|c|c|c|c|c|}
\hline Plant & Alive & Dead & Emigrated & $\begin{array}{l}\text { Lost to } \\
\text { follow up }\end{array}$ & Total \\
\hline $\begin{array}{l}\text { A } \\
\text { B } \\
\text { C } \\
\text { D } \\
\text { E } \\
\text { F } \\
\text { G } \\
\text { H } \\
\text { I }\end{array}$ & $\begin{array}{l}318 \\
75 \\
279 \\
652 \\
1040 \\
475 \\
1453 \\
1589 \\
681\end{array}$ & $\begin{array}{l}23 \\
3 \\
4 \\
32 \\
48 \\
11 \\
30 \\
113 \\
19\end{array}$ & $\begin{array}{l}19 \\
0 \\
4 \\
40 \\
27 \\
9 \\
30 \\
22 \\
12\end{array}$ & $\begin{array}{l}1 \\
0 \\
0 \\
1 \\
7 \\
1 \\
3 \\
2 \\
0\end{array}$ & $\begin{array}{l}361 \\
78 \\
287 \\
725 \\
1122 \\
496 \\
1516 \\
1726 \\
712\end{array}$ \\
\hline All (\%) & $6562(93.4)$ & $283(4 \cdot 0)$ & $163(2 \cdot 3)$ & $15(0 \cdot 2)$ & $7023(100)$ \\
\hline
\end{tabular}

those 4154 subjects employed for at least a year. ${ }^{5}$ Information on tumours (coded according to the International Classification of Diseases (ICD-7)) diagnosed from 1959 to 1987 , was obtained from the National Swedish Tumour Register. Altogether 119 subjects from the study base had been diagnosed as having cancer since their time of employment. For each case usually three referents were chosen from the study base. Incidence sampling was used-that is, referents were selected from those eligible to become cases at the (calendar) time of onset of each case. Also, cases and referents were matched with respect to plant, sex, and year of birth (to within one year for $73 \%$ of the matched sets; within six years for all sets). Individuals with the same type of cancer diagnosed before that of the case, were of course excluded from the set of potential referents. It was impossible to get any information on their job histories for five of the cases and 11 of the referents. Moreover, some referents were not eligible because their matched case had to be excluded. The analyses were therefore performed on 114 cases and 313 referents.

\section{PRODUCTION}

In all nine plants, TDI has been used in production $^{5}$; MDI has been used in eight of the plants. The start of exposure to TDI varied from 1958 to 1981 , and for MDI from 1964 to 1982 , for the different plants. The exact period for MDI handling in one of these plants could not be established. No cases or referents from that plant had, however, been exposed to MDI.

Block foaming - namely, foaming and expanding of low density materials $\left(<50 \mathrm{~kg} / \mathrm{m}^{3}\right)$ has taken place in four of the plants, both for sale and for further manufacturing within the plants. Today the blocks are stored in a separate room for at least three days before further handling. Thus the present exposure for most workers is low except for those directly involved in the foaming process. Earlier the blocks were stored within the production premises and used after 24 hours.

Dead cast moulding (eight plants) and further handling of the products (cell crushing, trimming, and assembling) have usually been located within the same premises. Thus workers other than moulders have been directly exposed to the isocyanates.

\section{ASSESSMENT OF EXPOSURE}

Work history for each case and referent was established by an occupational hygienist (HW). On the basis of the work histories, the individual exposures were rated for type of isocyanate, classification of amount of exposure to isocyanate, exposure frequency, and reliability of assessment for each employment period. The information was obtaine $\$$ by visiting the plants, abstracting personnes records, and interviewing plant personnel. The production processes were studied together with representatives of the managements, and the histories of the plants were established by the occupational hygienist after interviews and discussion with selected groups of persons with long employment and good personal knowledge of present and former employees. The interview committees represented members of the staff at the plants, foremen, trade unions, and health safety executives. All involved, including the occupational hygienist, made the assessments blind with respect to disease state.

The classifications used were:

Type of isocyanate: TDI, MDI, or TDI and MDI combined.

Isocyanate exposure level: $0=$ unexposed; $1=$ workplace in premises situated close to those used for foaming or moulding; $2=$ workplace in the premises used for foaming or moulding, but no personal handling of the substances; $3=$ direct exposure from the foaming or moulding processes. Frequency: $0 \%-100 \%$ of the workday.

Reliability: 1 = low; 2 = intermediate; 3 = high.

No exposure to isocyanates was defined as isocyanate exposure level $=0$, reliability $\geqslant 2$.

Intermediate exposure was defined as isocyanate exposure level $=2$ and reliability $\geqslant 2$ for TDI or TDI and MDI combined, or as isocyanate exposure level $\geqslant 2$ and reliability $\geqslant 2$ for MDI. 


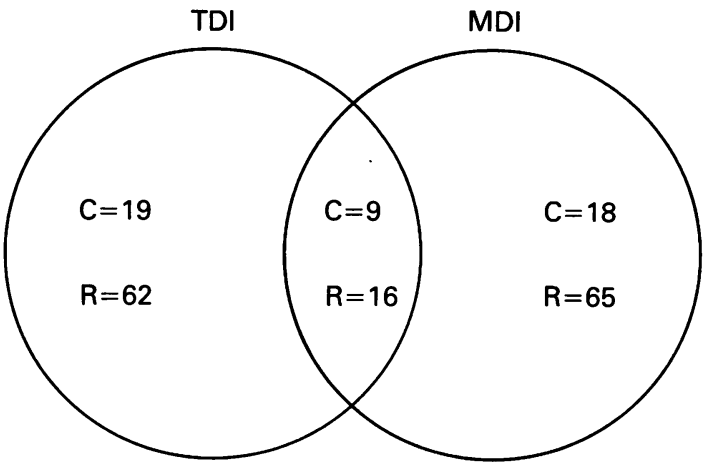

Figure Exposure to type of isocyanate for cases (C) and referents $(R)$. Only exposure levels $\geqslant 2$ are considered.

High exposure to isocyanates was defined as isocyanate exposure level $=3$ for TDI or TDI and MDI combined, and reliability $\geqslant 2$.

The remaining group of 85 subjects consisted of 21 subjects with a true low exposure (isocyanate exposure level $=1$, reliability $\geqslant 2$ ) and 64 subjects for which the uncertainty of their job histories was apparent (reliability $=1$ ).

The figure shows the crude exposure distribution for TDI and MDI among intermediate or highly exposed cases and referents.

Measurements of isocyanate exposure were normally performed only for fillers and moulders (isocyanate exposure level $=3$ ). These are also the most exposed groups. Isocyanate emission from foaming and moulding machines gave a considerable exposure also to employees in the same premises working mainly with cell crushing, trimming, and repairing (isocyanate exposure level $=$
2). These exposure levels may only be evaluated with a large uncertainty. The measured exposure to MDI was, with few exceptions, below $0.1 \mathrm{mg} / \mathrm{m}^{3}$ and normally below the detection limit of the analytical methods $\left(<0.01 \mathrm{mg} / \mathrm{m}^{3}\right)$. The TDI levels varied more; with the maximum levels between 0.026 and $3.0 \mathrm{mg} / \mathrm{m}^{3}$. Thus the most exposed group are the workers exposed to TDI in the block foaming and adjacent premises.

\section{STATISTICS}

The data were analysed by the conditional logistic regression model. 6 EGRET computer software (Statistics and Epidemiology Research Corporation, Seattle, US, 1990) was used for the analyses. The outcome effect measure of such analysis is the matched odds ratio (OR); under incidence sampling (already described), the matched OR is a consistent estimator of the incidence ratio and, as the diseases considered are rare, of the risk ratio as well. ${ }^{7}$ The ORs presented are thus adjusted with respect to the matching factors (age at risk, calendar year at risk, sex, and plant).

\section{Results}

Exposure to isocyanates was not associated with any increased overall risk of cancer, irrespective of exposure classification and induction latency period (table 2). This was true also for nonHodgkin's lymphomas and rectal cancer. On the other hand, non-significant increased risks were seen for colon cancer and prostate cancer. Four subjects with prostate cancer had been highly exposed $(\mathrm{OR}=2 \cdot 66,90 \%$ confidence interval (90\% CI) $0 \cdot 39-18 \cdot 1)$. This risk estimate did not

Table 2 Odds ratios (ORs) for various malignant tumours with respect to occupational exposure to isocyanates, with and without a 10 year induction latency period

\begin{tabular}{|c|c|c|c|c|c|c|c|c|c|c|}
\hline \multirow[b]{3}{*}{ Tumours } & \multicolumn{10}{|c|}{ Exposure to isocyanates } \\
\hline & \multirow{2}{*}{$\begin{array}{l}\text { None } \\
\text { No }\end{array}$} & \multicolumn{3}{|l|}{$A l{ }^{*}$} & \multicolumn{3}{|c|}{ Intermediate and high } & \multicolumn{3}{|c|}{ High } \\
\hline & & No & ORt & $(90 \% C I)$ & No & ORt & $(90 \% C I)$ & No & OR† & $(90 \% \mathrm{CI})$ \\
\hline \multicolumn{8}{|l|}{ No induction-latency period: } & & & \\
\hline All tumours & 39 & 75 & 0.87 & $(0.55-1 \cdot 38)$ & 46 & 0.65 & $(0.55-1 \cdot 38)$ & 15 & $0 \cdot 76$ & $(0.55-1 \cdot 38)$ \\
\hline Colon cancer & 2 & 6 & $2 \cdot 19$ & $(0 \cdot 48-10 \cdot 1)$ & 4 & 3.25 & $(0.50-21.3)$ & 1 & 0.69 & $(0.07-6.91)$ \\
\hline Rectal cancer & 2 & 5 & 0.58 & $(0 \cdot 10-3 \cdot 18)$ & 3 & 0.44 & $(0.07-2 \cdot 82)$ & 1 & 1.41 & $(0 \cdot 08-25 \cdot 6)$ \\
\hline Prostate cancer & 2 & 8 & 1.62 & $(0.38-6.90)$ & 7 & 2.96 & $(0 \cdot 45-19 \cdot 4)$ & 4 & 2.66 & $(0 \cdot 39-18 \cdot 1)$ \\
\hline Lymphoma and leukaemia: & 4 & 8 & 1.80 & $(0 \cdot 45-7 \cdot 25)$ & 3 & 0.73 & $(0 \cdot 12-4 \cdot 34)$ & 2 & 1.09 & $(0 \cdot 19-6 \cdot 18)$ \\
\hline Non-Hodgkin's lymphoma & $i$ & 3 & 0.74 & $(0 \cdot 09-6 \cdot 43)$ & 2 & $0 \cdot 67$ & $(0 \cdot 07-6 \cdot 19)$ & 1 & 0.52 & $(0.04-6 \cdot 20)$ \\
\hline \multirow{2}{*}{\multicolumn{11}{|c|}{$\begin{array}{l}10 \text { year induction latency period: } \\
\text { Referents }\end{array}$}} \\
\hline & 65 & 114 & & & 90 & & & 38 & & \\
\hline All tumours & 29 & 38 & $0 \cdot 74$ & $(0 \cdot 40-1 \cdot 36)$ & 22 & 0.56 & $(0 \cdot 29-1 \cdot 12)$ & 6 & 0.40 & $(0 \cdot 15-1 \cdot 05)$ \\
\hline Colon cancer & 0 & 4 & $\infty$ & & 3 & $\infty$ & & 0 & - & \\
\hline Rectal cancer & 2 & 2 & $0 \cdot 75$ & $(0 \cdot 13-4 \cdot 29)$ & 1 & $0 \cdot 40$ & $(-)$ & 0 & - & \\
\hline Prostate cancer & 3 & 5 & 1.07 & $(0 \cdot 25-4 \cdot 62)$ & 4 & 1.73 & $(0 \cdot 24-12 \cdot 3)$ & 2 & $2 \cdot 61$ & $(0 \cdot 28-24 \cdot 5)$ \\
\hline Lymphoma and leukaemia: & 4 & 6 & 0.51 & $(0.09-3.00)$ & 3 & 0.47 & $(0.07-2.99)$ & 1 & 0.34 & $(0.04-2.94)$ \\
\hline Non-Hodgkin's lymphoma & 1 & 3 & 0.88 & $(0 \cdot 09-8 \cdot 36)$ & 2 & 0.85 & $(0 \cdot 09-8 \cdot 30)$ & 1 & 0.66 & $(0.05-8 \cdot 40)$ \\
\hline
\end{tabular}

^Includes subjects with high, intermediate, and low exposure to isocyanates, and also the subjects for which the reliability of the exposure estimate $<2$.

tOR adjusted with respect to matching factors (age at risk, calendar year at risk, sex, plant). 
Table 3 Odds ratios (ORs) for all malignant tumours with respect to duration of exposure for those with a high occupational exposure to isocyanates, with and without a 10 years induction latency period

\begin{tabular}{|c|c|c|c|c|c|c|c|}
\hline \multirow[b]{3}{*}{ Tumours } & \multicolumn{7}{|c|}{ Exposure to isocyanates } \\
\hline & \multirow{2}{*}{$\begin{array}{l}\text { None } \\
\text { No }\end{array}$} & \multicolumn{3}{|c|}{$H i g h \leqslant 5 y$} & \multicolumn{3}{|c|}{ High $>5 y$} \\
\hline & & No & $O R^{*}$ & $(90 \% C I)$ & No & $O R^{*}$ & $(90 \% C I)$ \\
\hline \multicolumn{8}{|l|}{ No induction-latency period: } \\
\hline Referents & 102 & 38 & & & 13 & & \\
\hline All tumours & 39 & 46 & 0.76 & $(0 \cdot 37-1 \cdot 55)$ & 15 & $0 \cdot 78$ & $(0.56-1 \cdot 45)$ \\
\hline Colon cancer & 2 & 1 & & & 0 & & \\
\hline Rectal cancer & 2 & 1 & - & & 0 & - & \\
\hline Prostate cancer & 2 & 3 & - & & 1 & - & \\
\hline Lymphoma and leukaemia & 4 & 1 & - & & 1 & - & \\
\hline Non Hodgkin's lymphoma & 1 & 1 & - & & 0 & - & \\
\hline \multicolumn{8}{|l|}{10 years induction latency period: } \\
\hline Referents & 65 & 29 & & & 9 & & \\
\hline All tumours & 29 & 5 & 0.39 & $(0 \cdot 13-1 \cdot 15)$ & 1 & $0 \cdot 41$ & $(0 \cdot 07-2 \cdot 54)$ \\
\hline Colon cancer & 0 & 0 & & & 0 & & \\
\hline Rectal cancer & 2 & 0 & - & & 0 & - & \\
\hline Non Hodgkin's lymphoma & 1 & 1 & - & & 0 & - & \\
\hline
\end{tabular}

^OR adjusted with respect to matching factors (age at risk, calendar year at risk, sex, plant).

increase when a 10 year induction latency period was applied (OR $=2 \cdot 61,90 \%$ CI $0 \cdot 28-24 \cdot 5)$. Only one subject with colon cancer had been highly exposed to isocyanates $(\mathrm{OR}=0.69)$, and none assuming a 10 year induction latency period.

No difference in overall risk of cancer was seen between those highly exposed for more than five years $(O R=0.78)$ compared with those highly exposed for five years or less ( $O R=0.76$; table 3$)$. The ORs became even lower when applying a 10 year induction latency period. Only one case, with a prostate cancer, and none with a colon cancer, had been highly exposed for more than five years.

\section{Discussion}

The main finding of the present study was that the tentative associations, derived from the previous cohort study, ${ }^{5}$ between exposure to isocyanates and excess risk for non-Hodgkin's lymphomas and rectal cancer were not supported. Instead, non-significant associations with prostate cancer and possibly colon cancer were seen.

The present study was mainly performed to diminish the exposure misclassification that was obvious in the cohort design. ${ }^{5}$ There was an acceptable agreement between the assessments of exposure in the present case-referent study and in the cohort study, in spite of the sparse information available for the cohort study. This justifies the simple job exposure matrix used in the cohort study. In 47 randomly selected subjects from the case-referent study, 30 had corresponding assessments of exposure in the two studies. For 11 of the subjects, the isocyanate exposure level classification was higher in the case-referent study and for three subjects the reverse was true. For three subjects there was not enough information for a classification. Thus there was a tendency to underestimate the exposure to isocyanate in the cohort study. The information from the interview committees was far more productive than the information from the personnel records. The number of subjects in theg cohort study classified as being without exposures was reduced by $40 \%$ in the present study.

The lack of association between exposure to isocyanates and rectal cancer in the present study could be explained by reclassification of exposure. Out of the five subjects considered to have had apparent exposure to TDI or MDI in the cohort study, only one was considered highly exposed according to the present exposure assessment. Two of the remaining four subjects were considered to have intermediate exposure, one had a low exposure, and two had not been exposed at all.

As TDI had been used in all nine plants and MDI in all but one, and there were few cases of cancer, it was not feasible to separate the effect of exposure to TDI from that of MDI. Considering the airborne exposure it is obvious that the main contribution came from TDI. ${ }^{5}$ On the other hand, MDI might have been as important as TDI for the dermal uptake. Dermal absorption has not been considered specifically in the exposure assessments, but those workers with the most probable and pronounced dermal uptake were classified as having airborne isocyanate exposure level $=3$. Thus considering also dermal absorption there should not have to be any major reclassification of isocyanate exposure level.

One disadvantage with the isocyanate exposure level classifications used for TDI and MDI in the present studies is the lack of linear correspondence to isocyanate concentrations in air. Also, the classi- 
fication used is not uniform in terms of concentration in air between the different plants. The good reliability in the assessments used, however, is a great advantage. It would be possible to transform the classifications from the different plants to measures in terms of concentrations, but this would give a very complex exposure matrix and it is highly questionable if this would add to the information on the dose-response relations.

It seems obvious from our studies that occupational exposure to isocyanates does not cause an overall increased risk of cancer. Considering previous studies on occupational exposure to aromatic amines $^{8}$ and inhalation as the main occupational exposure route, we primarily expected to find excess risks of urinary bladder cancer and lung cancer. There was, however, no support at all for these hypotheses in our results.

The non-significant associations between exposure to isocyanates and prostate cancer and colon cancer respectively, may be spurious findings, but on the other hand, a true association cannot be excluded. No specific aetiological agent for prostate cancer has been identified, even if there are some indications of an excess risk for farmers, metal workers, mechanics, repairmen, and machine operators. ${ }^{9}$ We have also previously found an increased incidence of prostate cancer among workers manufacturing nitrate fertilisers. ${ }^{10}$ Colon cancer has mainly been associated with nutritional factors (a relative lack of dietary fibres and a high fat intake ${ }^{11}$ ) and sedentary jobs, ${ }^{12}$ but also with exposure to asbestos cement ${ }^{13}$ and cement dust. ${ }^{14}$ There is, however, increasing evidence that different subsites of colon do not share the same environmental risk factors. ${ }^{15}$ No odd distribution of localisation of colon cancer was seen in the present study (four out of eight cases of colon cancer were located in the upper colon, three in the colon descendens and sigmoideum, and one had an unspecified localisation). This must be considered as an argument against a causal association between exposure to isocyanates and risk of cancer.

The manufacture of polyurethane foam has involved not only isocyanates but also expanding agents, amine accelerators lubricants, and organic solvents. Theoretically, these exposures might act as confounding factors when studying the association between isocyanates and risk of cancer. On the other hand, these other chemical agents have varied substantially between the plants and the exposure to isocyanates has been the only common chemical characteristic of the plants. Chemical confounding is not a relevant problem of validity, in this case, as there was no significant association between risk of cancer and exposure to isocyanates.
It will, however, be possible to also assess exposure to potential chemical confounding factors in the future, if needed.

A follow up of this cohort will allow us to model exposure and risk of cancer on a greater number of cancer cases, which will increase the possibility of assessing the true association between exposure to isocyanates and risks of specific cancer.

Ms E Jonsson and Ms M Wikman are gratefully acknowledged for their valuable technical assistance. Representatives from the companies, company health services, the labour inspectorate, $\mathrm{Mr}$ Anders Holmén M Eng, and Mr Bengt Åkesson $\mathrm{PhD}$ are gratefully acknowledged for generously providing valuable information. The project was supported by grants from the Swedish Work Environment Fund and the Medical Faculty at the University of Lund.

1 International Agency for Research on Cancer. IARC monographs on the evaluation of the carcinogenic risk of chemicals to humans-some chemicals used in plastics and elastomers, vol 39, Lyon: IARC, 1986.

2 World Health Organisation. Environmental health criteria 75. Toluene diisocyanates. Geneva: WHO, 1987.

3 Persson P, Adamsson M, Dalene M, Skarping G, Hagmar L. Determination of occupational exposure to toluenediisocyanate by biological monitoring in urine and plasma by gas chromatography-mass spectrometry $\mathrm{Br} \mathcal{F}$ Ind Med (submitted).

4 Andersen M, Binderup M-L, Kiel P, Larsen H, Maxild J. Mutagenic action of isocyanates used in the production of polyurethanes. Scand 7 Work Environ Health 1980;6:221-6.

5 Hagmar L, Welinder $\mathbf{H}$, Mikoczy $Z$. Cancer incidence and mortality in the Swedish polyurethane foam manufacturing industry. Br f Ind Med 1993;50:537-43.

6 Hosmer DW, Lemeshow S. Applied logistic regression. New York: Wiley, 1989

7 Greenland S, Thomas DC. On the need for the rare disease assumption in case-control studies. Am F Epidemiol 1982; 116:547-53.

8 Clayson DB. Occupational bladder cancer. Prev Med 1976; $5: 228-44$

9 van der Gulden JWJ, Kolk JJ, Verbeek ALM. Prostate cancer and work environment. F Occup Med 1992;34:402-9.

10 Hagmar L, Bellander T, Andersson C, Lindén K, Attewell R, Möller T. Cancer morbidity in nitrate fertilizer workers. Int Arch Occup Environ Health 1991;63:63-7.

11 Weisburger JH, Wynder EL, Horn CL. Nutritional factors and etiologic mechanisms in the causation of gastrointestinal cancers. Cancer 1982;50:2541-9.

12 Garabrant DH, Peters JM, Mack TM, Bernstein L. Job activity and colon cancer risk. Am $\mathcal{F}$ Epidemiol 1984;119: 1005-14.

13 Albin M, Jakobsson K, Attewell R, Johansson L, Welinder $\mathrm{H}$. Mortality and cancer morbidity in cohorts of asbestos cement workers and referents. $\mathrm{Br} \mathcal{F}$ Ind $\mathrm{Med}$ 1990;4: 602-610.

14 Jakobsson $\mathrm{K}$, Horstmann V, Welinder H. Mortality and cancer morbidity among cement workers. $\mathrm{Br} \mathcal{F}$ Ind $\mathrm{Med}$ 1993;50:264-72.

15 Peters RK, Garabrant DH, Yu MC, Mack TM. A case control study of occupational and dietary factors in colorectal cancer in young men by subsite. Cancer Res 1989;49: $5459-68$.

Accepted 18 January 1993 